\title{
Correction to: Foundations for a Comparative Research Programme Between Wine Markets in the Twentieth Century
}

\section{Romain Blancaneaux}

\section{Correction to:}

Chapter "Foundations for a Comparative Research Programme Between Wine Markets in the Twentieth Century" in:

S. A. Conca Messina et al. (eds.), A History of Wine in Europe, 19th to 20th Centuries, Volume II, Palgrave Studies in Economic History, https://doi.org/10.1007/978-3-030-27794-9_10

The original version of this chapter was inadvertently published with author's forename and surname interchanged. The interchanged name Blancaneaux Romain has now been corrected to Romain Blancaneaux. The chapter has been updated with the corrections. 